\title{
Prelimenary Investigation of Parametric Optimization on Turning Process Using UVAT Tool Holder Based on Taguchi Method
}

\author{
Haris Rachmat ${ }^{1,2}$, Mohd Rasidi Ibrahim ${ }^{1}$, and Sulaiman Hasan ${ }^{1}$ \\ ${ }^{1}$ Premach FKMP University Tun Husein Onn Malaysia, Batu Pahat 8400 Malaysia. \\ ${ }^{2}$ School of Industrial Engineering Telkom University, Bandung, Indonesia.
}

\begin{abstract}
Determining of cutting parameters on cutting forces and cutting temperatures is critical during the turning operation. Most of the research is focused on cutting using special toolholder for conventional turning. In this study, the main objective is to study effect of cutting speed, feed rate and depth of cut on cutting force and cutting temperature of alumunium alloy (Al6061-T6) in turning operation. Two different design of UVAT toolholders (D1 and D2) were conducted. Experiments have been applied using Taguchi's experimental design technique. An orthogonal array, signal to noise ratio, and analysis of variance are employed to investigate cutting characteristics of each design. Experimental results show that cutting speed is the most significant machining parameter on cutting forces and cutting temperatures. Continously were followed by feed rate and depth of cut. The lowest cutting force and cutting temperature were obtained when the setting of cutting parameters are cutting speed is 50 $\mathrm{m} / \mathrm{min}$, feed rate is $0.05 \mathrm{~mm} / \mathrm{nin}$ and depth of cut is $0.25 \mathrm{~mm}$.
\end{abstract}

\section{Introduction}

In modern era, the adoption of new technologies in various sectors is highly required. Ultrasonic vibration is one of the new technologies implemented in various manufacturing areas such as ultrasonic welding, ultrasonic assisted turning, ultrasonic assisted drilling, ultrasonic assisted milling etc., and ultrasonics are also used in medical applications.

Ultrasonic vibration assisted turning (UVAT) is proposed to provide an alternative towards reduction of excessive plastic deformation during the machining process of advanced materials [1]. Ultrasonic assisted turning is a cutting technique in which a certain frequency (in ultrasonic range) of vibration is applied to the cutting tool or the work-piece (besides the original relative motion between these two) to achieve better cutting performance [2]. Ductile mode of cutting can also be achieved which induces good compressive residual stresses in the workpiece during dry cutting process. High frequency and low amplitude motion during UVAT which imparted on the tool insert against the rotating work piece has benefitted the cutting tool life with great cutting force reduction and production of good surface finish [3].

Corresponding author: rasidi@uthm.edu.my 
The fundamental difference between conventional turning (CT) and UVAT in terms of tool holder is the presence of a place for the installation of piezoelectric actuator (PZT) on UVAT, as long as there is no in CT. Ultrasonic vibrations in the tool holder are generated by piezoelectric actuators. Vibration with frequencies above $20 \mathrm{kHz}$ is propagated through the tool holder to the cutting tool. The tool will vibrate in an ultrasonic frequency during the turning process is run .

Many research works $[4,5,6,7]$ have proposed the use of UVAT in order to cut various advanced materials (Titanium, Inconel, Aluminium matrix composite and others). However, at present the ultrasonic assisted turning process applies customized cutting tool assemblies. This includes different type of tool holders, dissimilar PZT and uncommon position of the PZT embedment. The former provides that each researcher has their own unique proposals on the application of UVAT process.

Traditionally, the selection of cutting conditions for turning process is left to the machine operator. In such cases, the experience of the operator plays a major role, but even for a skilled operator it is very difficult to attain the optimum values each time. There are various machining parameters affecting the output of turning process. Among these parameters, cutting speed, feed rate and depth of cut are the primary parameters that should be selected properly for machining process to ensure good surface quality and to prolong tool life. The effect of cutting parameters on cutting force, cutting temperature, surface roughness and tool life have been modelled by various researchers $[8,9,10]$.

The present study proposes prelimenary investigation of machining parametric optimization on conventinal turning process using UVAT tool holder with the aim of Taguchi method. The machining parameters were used to result of cutting force and cutting temperature. Two different UVAT tool holder design (D1 and D2) were conducted to perform the machining process and each of it used same cutting tool. In this study three levels of speed, feed and depth of cut are evaluated.

\section{Taguchi Method}

The method presented in this study is an experimental design process called the Taguchi design method. The method is an efficient and complex technique for optimization primarily to improve quality, cost and performance design. This method is widely used in various fields of engineering for the design of experimental planning. The approach of this method is to reduce the number of experiments using a special orthogonal circuit developed by Taguchi. With this method, it is possible to obtain process optimization while simultaneously minimizing the sensitivity of experimental external variation [11]

The result of this method is expected that the optimal process parameters obtained from the parameter design are not sensitive to the variation of environmental conditions and other noise factors. Therefore, parameter design is a key step in Taguchi's method of achieving high quality without increasing cost [12].

In Taguchi method, the main parameters have influence on process results, which are positioned at different rows in a designed orthogonal array. The difference between the functional value and objective value is recognized as the loss function that can be expressed by signal-to-noise $(\mathrm{S} / \mathrm{N})$ ratio.

Regardless of the category of the performance characteristic, the larger $\mathrm{S} / \mathrm{N}$ ratio corresponds to the better performance characteristic. Therefore, the optimal level of the process parameters is the level with the highest $\mathrm{S} / \mathrm{N}$ ratio. Furthermore, a larger $\mathrm{S} / \mathrm{N}$ ratio is associated with better performance characteristics. Therefore, the level with the highest $\mathrm{S} / \mathrm{N}$ ratio indicates the optimal level of process parameters. Furthermore, an analysis of variance (ANOVA) is performed to see which process parameters are statistically 
significant. According to $\mathrm{S} / \mathrm{N}$ and ANOVA analysis, optimal combinations of process parameters can be predicted.

\section{Methodology}

\subsection{Design of Uvat Tool Hoder}

There are 2 designs used in this study. Both of of these designs have similarities in geometry and the type of cutting tool. There is a fundamental difference in the number of parts used. It lies in the place to put the PZT as a generator of ultrasonic vibration. Ultrasonic vibration in the tool holder propagates to the insert part. Kyocera's VBMT is used as a cutting insert that is specified for the finishing process.

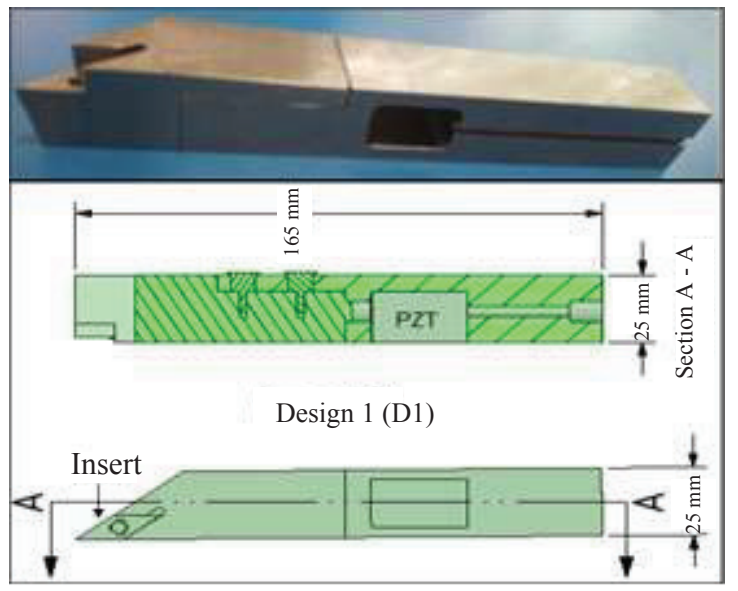

Fig. 1. Tool holder design 1 (D1)

The first design (D1), the design is divided into 2 parts, namely the head and body as shown in Figure 1. Bolts are made of the same material such as AISI 1045. Both are separated and put together using a $4 \mathrm{~mm}$ bolt with a depth of $10 \mathrm{~mm}$. Vibration which generate from PZT is propagated on the cutting tool past the pin mounted on the head that will move linearly.

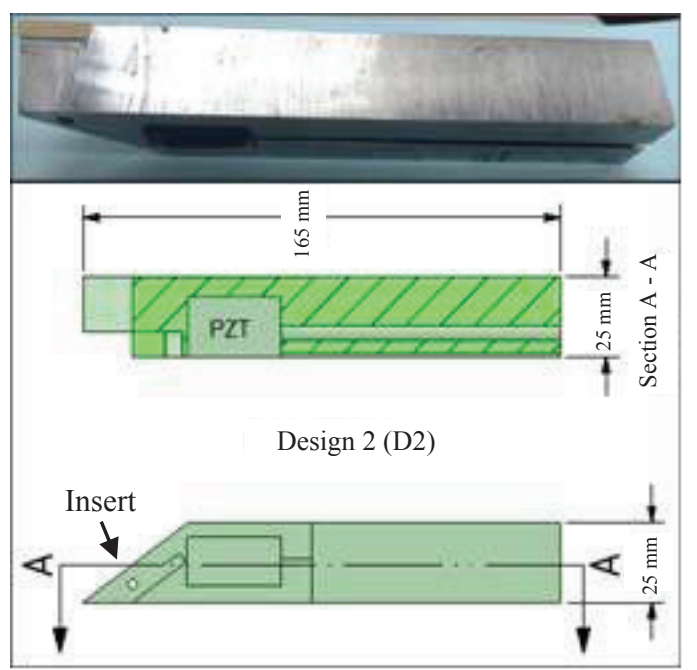

Fig. 2. Tool holder design 2 (D2) 
The second design (D2), there is no separated parts in this tool holder's design. It is made from stainless steel 201 as shown in Figure 2. The ultrasonic vibration is propagated towards the tool insert directly through the tool's structure.

\subsection{Machining experiment}

The turning experiments were performed using Harrison Alpha 400 lathe machine. In this study, the value of cutting speed, cutting depth and feed speed were varied. There are nine variations where the cutting speed, the feed rate is the same, but the depth of cut is varies.

Experiment is done by lathe surface of workpiece made of allumunium AL 6061 T6. The inserted TNT-mounted insert tool holder is installed on the lathe and the turning operation is performed $10 \mathrm{~mm}$ long.

During the dry-cutting process is carried out, a measurement of cutting force using the 9257 B Kistler Dynamometer model. Dynamometer was attached to the tool holder and was supported by charge amplifier and signal conditioning to measure cutting forces. Dynoware software was connected to the dynamometer for recording purposes. The charge generated at the dynamometer was amplified using multi channel charge amplifier (type 5070A). The sensitivities of the multi-channel charge amplifiers were set for $-7.939 \mathrm{pC} / \mathrm{N}$ for normal force $(\mathrm{Fx}),-7.960 \mathrm{pC} / \mathrm{N}$ for feed force $(\mathrm{Fy})$, and $-3.722 \mathrm{pC} / \mathrm{N}$ for axial force $(\mathrm{Fz})$. The sampling frequency of data was set at 7,000 Hz. This experimental setup can be seen in Figure 3 below.

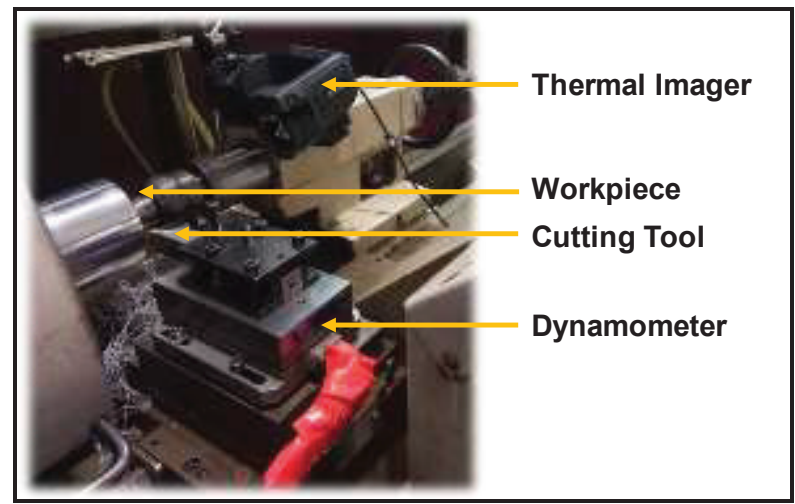

Fig. 3. Experimental setup

The temperature has been measured using infrared thermal camera FLIR T640. FLIR tool+ software was used to record temperature and to analyse the thermal image. This thermal camera has high thermal sensitivity of $\leq 60 \mathrm{mk}$ at $30^{\circ} \mathrm{C}$. The temperature range is from $-20^{\circ} \mathrm{C}$ to $2000^{\circ} \mathrm{C}$ with high accuracy. The result of the measurement of these two machining outputs is then used as object for analysis.

\subsection{Experimental design and parameter selection}

There are three cutting parameters: cutting speed, feed rate and depth of cut has been considered for three levels (low, medium, high). Three variables are studied for three levels and hence nine experiments were designed. L9 orthogonal array had been used in this study as it has the capability to perform parametric study with three factors and three levels.

As shown in Table 1, three cutting parameters have been selected to conduct the experiment. The number of experiments and combination of cutting parameters and level for L9 orthogonal array is shown in Table 2. 
Table 1. Experimental parameters and their levels.

\begin{tabular}{|c|c|c|c|}
\hline \multirow{2}{*}{ Factors } & \multicolumn{3}{|c|}{ Level } \\
\cline { 2 - 4 } & 1 (Low) & 2 (Medium) & 3 (High) \\
\hline A: Cutting speed $(\mathrm{m} / \mathrm{min})$ & 50 & 75 & 100 \\
\hline B: Feed rate $(\mathrm{mm} / \mathrm{min})$ & 0.05 & 0.08 & 0.1 \\
\hline C: Depth of cut $(\mathrm{mm})$ & 0.25 & 0.375 & 0.5 \\
\hline
\end{tabular}

Table 2. L9 orthogonal array.

\begin{tabular}{|c|c|c|c|}
\hline \multirow{2}{*}{ Trial number } & \multicolumn{3}{|c|}{ Control factor } \\
\cline { 2 - 4 } & A:Cutting speed & B: Feed rate & C:Depth of cut \\
\hline 1 & 1 & 1 & 1 \\
\hline 2 & 1 & 2 & 2 \\
\hline 3 & 1 & 3 & 3 \\
\hline 4 & 2 & 1 & 1 \\
\hline 5 & 2 & 2 & 2 \\
\hline 6 & 2 & 3 & 3 \\
\hline 7 & 3 & 1 & 1 \\
\hline 8 & 3 & 2 & 2 \\
\hline 9 & 3 & 3 & 3 \\
\hline
\end{tabular}

\section{Results and Discussion}

The response table, which contains the sums of the $\mathrm{S} / \mathrm{N}$ ratios for each level and for each factor is shown in the Table 3 . The category the smaller the better was used to calculate $\mathrm{S} / \mathrm{N}$ ratio for cutting force and cutting temperature according to the equation:

$$
\mathrm{S} / \mathrm{N}_{\mathrm{s}}=-10 * \log \left(\frac{1}{n} \sum_{i=1}^{n} y_{i}^{2}\right)
$$

where $\mathrm{y}$, is the average of observed data, $\mathrm{S}_{\mathrm{y}}{ }^{2}$ is the variance of $\mathrm{y}, \mathrm{n}$ is the number of observations and $\mathrm{y}$ is the observed data. Notice that these $\mathrm{S} / \mathrm{N}$ ratios are expressed on a decibel scale. We would use $\mathrm{S} / \mathrm{N}_{\mathrm{T}}$ if the objective is to reduce variability around a specific target, $\mathrm{S} / \mathrm{N}_{\mathrm{L}}$ if the system is optimized when the response is as large as possible, and $\mathrm{S} / \mathrm{N}_{\mathrm{S}}$ if the system is optimized when the response is as small as possible. Factor levels that maximize the appropriate $\mathrm{S} / \mathrm{N}$ ratio are optimal.

Table 3. Experimental result

\begin{tabular}{|c|c|c|c|c|c|c|c|}
\hline \multirow{2}{*}{$\begin{array}{c}\text { Trial } \\
\text { no }\end{array}$} & \multicolumn{2}{|c|}{ Machining parameters } & \multicolumn{2}{c|}{ Output response } & \multicolumn{2}{c|}{ S/N Ratio } \\
\cline { 2 - 8 }$(\mathrm{m} / \mathrm{min})$ & $\begin{array}{c}\mathbf{B} \\
(\mathrm{mm} / \mathrm{min})\end{array}$ & $\begin{array}{c}\mathbf{C} \\
(\mathrm{mm})\end{array}$ & $\begin{array}{c}\mathbf{C F} \\
(\mathbf{N})\end{array}$ & $\begin{array}{c}\mathbf{C T} \\
\left({ }^{\circ} \mathbf{C}\right)\end{array}$ & $\mathbf{C F}$ & $\mathbf{C T}$ \\
\hline 1 & 50 & 0,05 & 0,25 & 21,99 & 47,00 & $-26,84$ & $-33,44$ \\
\hline 2 & 50 & 0,05 & 0,375 & 30,39 & 49,87 & $-29,65$ & $-33,96$ \\
\hline 3 & 50 & 0,05 & 0,5 & 42,17 & 53,11 & $-32,50$ & $-34,50$ \\
\hline 4 & 50 & 0,08 & 0,25 & 31,79 & 54,21 & $-30,05$ & $-34,68$ \\
\hline 5 & 50 & 0,08 & 0,375 & 44,35 & 56,84 & $-32,94$ & $-35,09$ \\
\hline 6 & 50 & 0,08 & 0,5 & 68,54 & 81,31 & $-36,72$ & $-38,20$ \\
\hline 7 & 50 & 0,1 & 0,25 & 35,09 & 60,21 & $-30,90$ & $-35,59$ \\
\hline
\end{tabular}




\begin{tabular}{|c|c|c|c|c|c|c|c|}
\hline 8 & 50 & 0,1 & 0,375 & 49,02 & 67,18 & $-33,81$ & $-36,55$ \\
\hline 9 & 50 & 0,1 & 0,5 & 62,5 & 78,06 & $-35,92$ & $-37,85$ \\
\hline 10 & 75 & 0,05 & 0,25 & 39,08 & 60,01 & $-31,84$ & $-35,57$ \\
\hline 11 & 75 & 0,05 & 0,375 & 43,37 & 64,39 & $-32,74$ & $-36,18$ \\
\hline 12 & 75 & 0,05 & 0,5 & 45,47 & 65,32 & $-33,15$ & $-36,30$ \\
\hline 13 & 75 & 0,08 & 0,25 & 44,4 & 66,82 & $-32,95$ & $-36,50$ \\
\hline 14 & 75 & 0,08 & 0,375 & 58,02 & 74,12 & $-35,27$ & $-37,40$ \\
\hline 15 & 75 & 0,08 & 0,5 & 64,22 & 89,38 & $-36,15$ & $-39,02$ \\
\hline 16 & 75 & 0,1 & 0,25 & 47,93 & 58,82 & $-33,61$ & $-35,39$ \\
\hline 17 & 75 & 0,1 & 0,375 & 58,6 & 71,92 & $-35,36$ & $-37,14$ \\
\hline 18 & 75 & 0,1 & 0,5 & 78,36 & 82,28 & $-37,88$ & $-38,31$ \\
\hline 19 & 100 & 0,05 & 0,25 & 35,35 & 65,39 & $-30,97$ & $-36,31$ \\
\hline 20 & 100 & 0,05 & 0,375 & 44,71 & 67,79 & $-33,01$ & $-36,62$ \\
\hline 21 & 100 & 0,05 & 0,5 & 54,82 & 76,36 & $-34,78$ & $-37,66$ \\
\hline 22 & 100 & 0,08 & 0,25 & 52,39 & 57,21 & $-34,38$ & $-35,15$ \\
\hline 23 & 100 & 0,08 & 0,375 & 68,83 & 63,42 & $-36,76$ & $-36,05$ \\
\hline 24 & 100 & 0,08 & 0,5 & 71,31 & 71,63 & $-37,06$ & $-37,10$ \\
\hline 25 & 100 & 0,1 & 0,25 & 42,03 & 61,11 & $-32,47$ & $-35,72$ \\
\hline 26 & 100 & 0,1 & 0,375 & 63,69 & 68,47 & $-36,08$ & $-36,71$ \\
\hline 27 & 100 & 0,1 & 0,5 & 80,27 & 70,80 & $-38,09$ & $-37,00$ \\
\hline
\end{tabular}

\subsection{Cutting Force}

The effect of cutting parameters on cutting forces can be described using the response graph of $\mathrm{S} / \mathrm{N}$ ratio. However, the percentage contribution for each factor cannot be determine using the graph. Pareto ANOVA is used to show the percentage contribution for the factors. Its simplified ANOVA by providing simple and faster step to determine the contribution of selected factor on experimental response.

The effect of changing parameters for different design (D1 and D2) is shown in Figure 4 (a) and (b) respectively. The response graph and pareto ANOVA (Figure 5 (a) and (b)) showed that the combinations of cutting speeds and feedrates have significantly effected on cutting force for both design. However, cutting speed had the strongest effect at $47.1 \%$ for D1 while feed rate contributes $32.26 \%$ and depth of cut $20.73 \%$. Figure 5 (a) indicates to get the lowest cutting force in machining when used D1, low cutting speed (A1), feedrate(B1) and depth of cut $(\mathrm{C} 1)$ is required.

The result for D2 as shown in Figure 5 (b) agreed with D1, which showed that the most significant effect is the cutting speed and followed by feed rate. The percentage contribution of feedrate and cutting speed is $22.80 \%$ and $61.13 \%$ respectively. However, to get lower cutting forces A1 and B1 are preferred.

The percentage contribution of depth of cut shown that the influence of this parameter on cutting forces for both design is the lowest. 


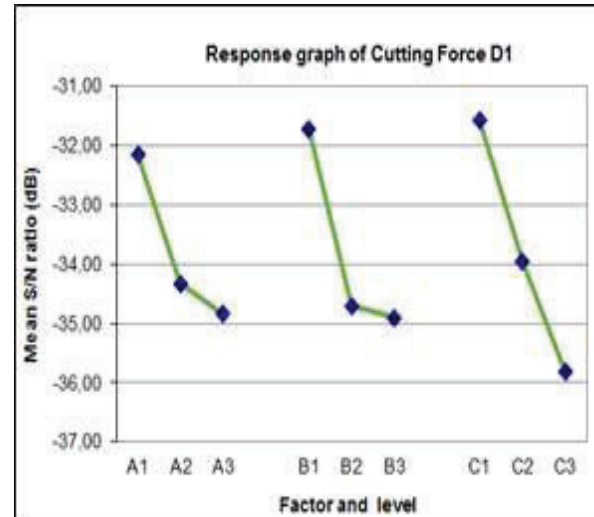

(a)

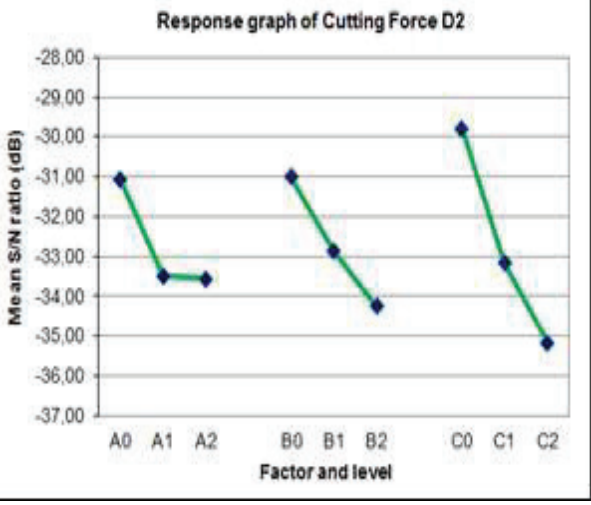

(b)

Fig. 4. Effect of cutting parameters on cutting force :

(a) Design 1, (b) Design 2

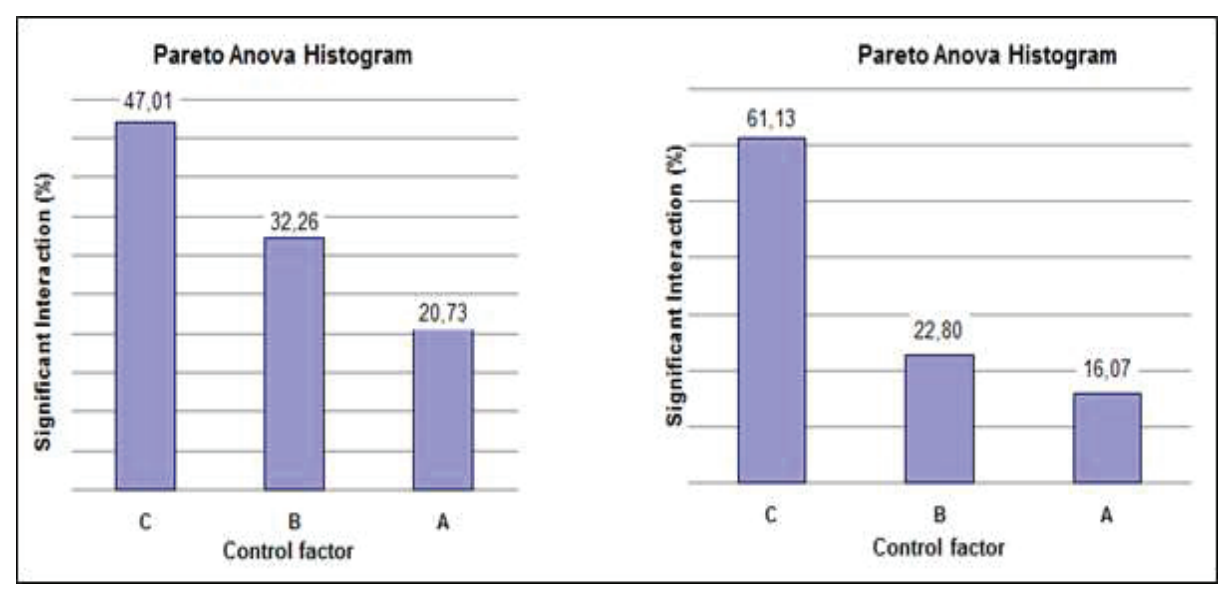

(a)

(b)

Fig. 5. Percentage contribution of cutting parameters on cutting force :

(a) Design 1, (b) Design 2

\subsection{Cutting temperature}

Many factors affect cutting temperature during machining process. The factors include the properties of cutting material and cutting tool as well as geometry of the cutting tool. According [8], these factors and cutting parameters such as cutting speed feedrate and depth of cut have significant contribution to the temperature of the cutting area.

Response graph in Figure 6 (a) and (b) and Pareto ANOVA in Figure 7 (a) and (b) shows the effect of selected cutting parameters on cutting temperature. The graph 7 (a) shows that cutting speed is the most influential cutting parameter on cutting temperature for D1 with $45.76 \%$ contribution. Similar result was obtained in Figure 7 (b) for D2 with $53.99 \%$ contribution on cutting temperature came from cutting speed. This is due to the adiabatic effect at high cutting speed caused by the trapped heat in the shear deformation zone. The heat cannot escape in the very short time during the process causing highly localized temperatures in the chip[8].

Correspondingly, there is a similarity of feed rate effect and depth of cut for both designs. Feed rate has a greater influence on the cutting temperature for D1 and D2. 
Whereas, the depth of cut has the least influence of the three parameters tested. The results show that the depth of cut has a weak effect on cutting temperature. This is influenced by the thinness of the cutting depth so it did not required a large amount of cutting force.

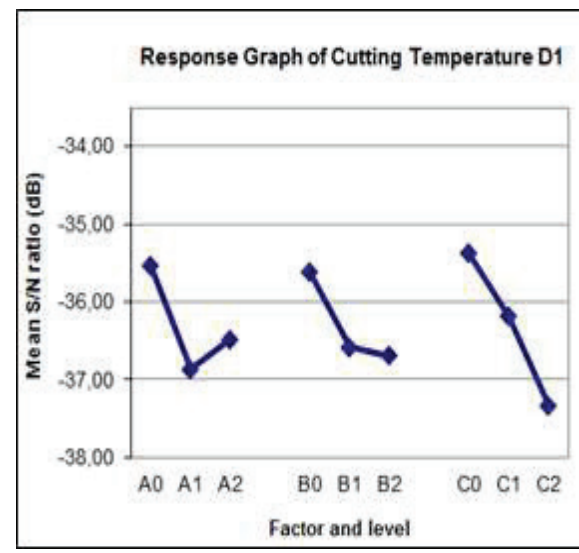

a)

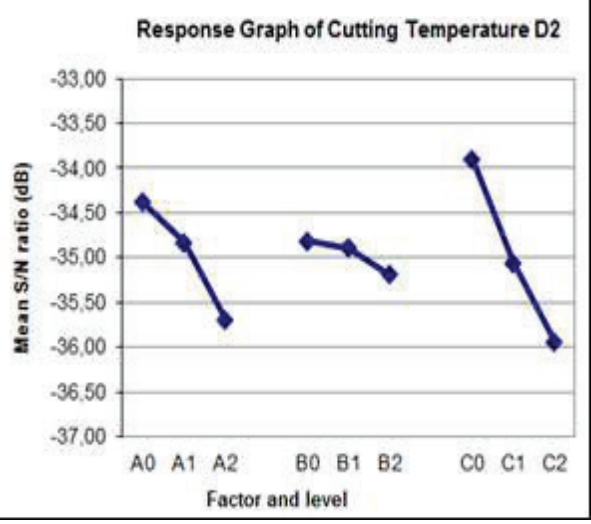

(b)

Fig. 6. Effect of cutting parameters on cutting temperature :

(a) Design 1, (b) Design 2

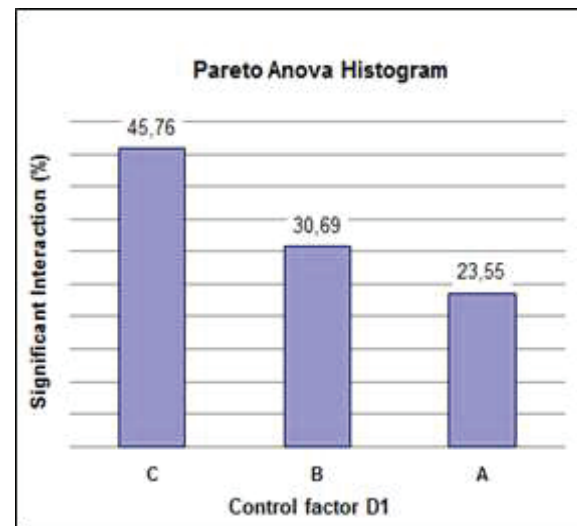

(a)

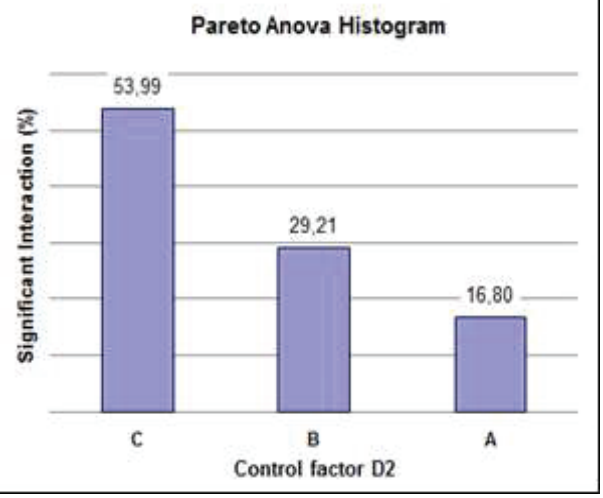

(b)

Fig. 7. Percentage contribution of cutting parameters on cutting force :

(a) Design 1, (b) Design 2

\section{Conclusion}

The experiment has demonstrated an application of the Taguchi method for investing the effects of cutting parameters on cutting force and cutting temperature in turning aluminum metal. With analysis of results in this study using $\mathrm{S} / \mathrm{N}$ ratio approach and ANOVA provides a systematic and efficient methodology for the optimization of cutting parameters.

The cutting force and cutting temperature on D1 and D2 are mainly affected by cutting speed, feed rate and depth of cut, by decreasing any one the force and temperature is decreased. The parameters considered in this experiment are optimized to attain minimize force and temperature when machining run. The best parameters on cutting force for D1 and D2 have similarity. The parameters are cutting speed at $50 \mathrm{~m} / \mathrm{min}$, feed rate at 0,05 
$\mathrm{mm} / \mathrm{min}$ and depth of cut at $0,025 \mathrm{~mm}$. According to Anova analysis on cutting forcr for D1 and D2, the cutting speed has highly influence and followed by feed rate and depth of cut.

However with cutting force, the best parameters on cutting temperatures D1 and D2 also have similarity. Cutting speed parameters at $50 \mathrm{~m} / \mathrm{min}$, feed rate at $0.05 \mathrm{~mm} / \mathrm{min}$ and cutting depth at $0.025 \mathrm{~mm}$ are parameters that can be used to perform the minimum cutting temperature. Similarly, based on Anova's analysis of cutting temperature for D1 and D2, cutting speed is very influential and followed by feed rate and cutting depth.

\section{Acknowledgement}

This paper was supported by UTHM GIPS grant monitored by Office for Research, Innovation, Commercialization and Consultancy (ORICC) UTHM Malaysia. Additional support was received from Precission Machining Research Center (FKMP - UTHM) and FRI - Telkom University Indonesia.

\section{References}

[1] Sharma \& Pandey, Recent advances in ultrasonic assisted turning: A step towards sustainability, Cogent Engineering, 3: 1-20 (2016).

[2] H. Rachmat, M. R. Ibrahim, and S. Hasan, Design selection of an innovative tool holder for ultrasonic vibration assisted turning (IN-UVAT) using finite element analysis simulation, AIP Conference Proceedings 1831, 020029 (2017).

[3] D. E. Brehl and T. A. Dow, Review of vibration-assisted machining, Precision Engineering, 32, 153-172 (2008).

[4] Y. Xing, , J. Deng, and J. Zhao, Cutting performance and wear mechanism of nanoscale and microscale textured Al2O3/TiC ceramic tools in dry cutting of hardened steel, International Journal of Refractory Metals and Hard Materials, 43, 46 -58 (2014).

[5] A.Maurotto, R. Muhammad, A. Roy, and V. V. Silberschmidt, Enhanced ultrasonically assisted turning of a $\beta$-titanium alloy, Ultrasonics, 53, 1242-1250 (2013).

[6] M. R. Ibrahim, Experimental Analysis on Ultrasonic Assisted Turning (UAT) Based on Innovated Tool Holder in the Scope of Dry \& Wet Machining, Applied Mechanics and Materials, Vol: 660, 8, pp. 104-108, (2014).

[7] H. Rachmat, T. Mulyana, S. Hasan, M. R Ibrahim, Design Selection of In-UVAT Using MATLAB Fuzzy Logic Toolbox, Recent Advances on Soft Computing and Data Mining book series (AISC, volume 549), pp 538-545, (2017).

[8] M. Bacci da Silva and J. Wallbank, Cutting temperature: prediction and measurement methods-a review, J. Matel Process Technology, vol 8 no 1- 3, pp. 195-202, (1999).

[9] W.H Yang and Y.S Tarng, Design Optimization of Cutting Parameters for Turning Operations based on the Taguchi Method, Journal of Materials Processing Technology, Vol. 84, pp. 122 - 129, 1998.

[10] A. Manna, S. Salodkar, Optimization of machining conditions for effective turning of E0300 alloy steel. Journal of Materials Processing Technology, vol. 203, pp. 147-153, (2008).

[11] M. Kaladhari and K.V Subbaiah, Application of Taguchi approach and Utility Concept in solving the Multi-objective Problem when turning AISI 202 Austenitic 
Stainless Steel, Journal of Engineering Science and Technology Review 4 (1) : pp. 55 61 (2011).

[12] M. Sanyilmaz, Application Taguchi method on experimental design and quality dvelopment, Master Thesis, Applied Natural Science Institute, Dumlupinar University, Kutahya. (2006). 